\title{
РАЗРАБОТКА УСЛОВИЙ ПОЛУЧЕНИЯ СЛАБООКРАШЕННОГО СОСНОВОГО МАСЛА
}

\author{
() Т.И. Долинский ${ }^{1}$ И.С. Ильичев ${ }^{1}$, А.А. Шалачова ${ }^{2}$, А.С. Новоселов ${ }^{2}$, Е.А. Маврина ${ }^{2}$, \\ Л.Л. Семенычева ${ }^{2} *$ \\ '3АО «Торговый дом «Оргхим», пр. Гагарина, 29д, Нижний Новгород, 603950 \\ (Россия) \\ ${ }^{2}$ Нижегородский госуниверситет им. Н.И. Лобачевского, пр. Гагарина, 23, \\ Нижний Новгород, 603950 (Россия), e-mail:Ilsem@yandex.ru
}

\begin{abstract}
Приводятся данные об условиях получения слабоокрашенного соснового масла из соснового масла-сырца с цветностью не более 30 по шкале Хазена. В качестве объекта исследований использовали сульфатный скипидар Усть-Илимского ЛПК, соответствующий ТУ 2416-009-51501169-2005. Синтез МС проводили по известной методике, количественный анализ состава скипидара и продуктов ректификации осуществляли методом газовой хроматографии на приборе «Кристалл-Люкс 4000М» с пламенно-ионизационным детектором. Выбор условий ректификации соснового масла-сырца осуществляли с использованием лабораторной установки из стекла, а также пилотной установки периодического действия. Состав фракций при этом практически не отличался при ректификации на лабораторной и пилотной установках. Данные о ректификации хорошо воспроизводятся в серии экспериментов. Парфюмерный терпинеол является последней фракцией перегонки, предыдущие фракции имеют самостоятельное значение. Лабораторная технология ректификации МС-сырца для получения слабоокрашенного МС является фрагментом разработки технологии получения в едином технологическом потоке продуктов переработки скипидара: соснового масла, терпингидрата, парфюмерного терпинеола и др.
\end{abstract}

Ключевые слова: сульфатный скипидар, сосновое масло, ректификация, парфюмерный терпинеол.

Работа выполнена в Нижегородском государственном университете при финансовой поддержке Министерства Образования и Науки РФ (договор №02.G25.31.0073).

\section{Введение}

Масло сосновое (МС) является крупнотоннажным продуктом переработки сульфатного скипидара продукта сульфатной варки целлюлозы, т.е. представляет собой возобновляемое сырье. МС применяется в составе лакокрасочных композиций, жидких бактерицидных препаратов, обладает прекрасными флотирующими свойствами, а высококачественное МС, с большим содержанием терпеновых спиртов, используют для получения парфюмерного терпинеола [1-4]. МС-сырец является продуктом кислотно-катализируемой

Долинский Тарас Иванович - руководитель исследовательского центра

Ильичев Илья Сергеевич - кандидат химических наук, руководитель проекта «Развитие лесохимии»

Шалашова Александра Аркадьевна - младший научный сотрудник

Новоселов Артемий Сергеевич - младший научный сотрудник

Маврина Екатерина Александровна - младший научный сотрудник

Семенычева Людмила Леонидовна - доктор химических наук, старший научный сотрудник, заведующая лабораторией НИИХ, e-mail: llsem@ yandex.ru гидратации сульфатного скипидара [1-5], которая приводит к получению целого ряда продуктов: $\alpha-, \beta-$, и $\gamma$-терпинеолов, монотерпеноидов моно- и бициклического строения, а также низкомолекулярных олигомеров монотерпеновых углеводородов, преимущественно димеров. Эта смесь и представляет собой технический МС-сырец, из которого ректификацией выделяют целевые продукты. В связи с этим совершенствование условий выделения качественного МС является важной и актуальной задачей.

\footnotetext{
* Автор, с которым следует вести переписку.
} 
Целью данной работы является выбор условий ректификации МС-сырца с использованием лабораторной установки из стекла, а также пилотной установки периодического действия, при этом главной задачей представляется получение слабоокрашенного МС (цветность по шкале Хазена неболее 30), содержащего не менее $70 \%$ смеси изомеров терпинеола. Разработка опирается на доступное отечественное сырье и предполагает в дальнейшем разработку технологии промышленного производства.

\section{Экспериментальная часть}

В работе использовали сульфатный скипидар Усть-Илимского ЛПК, соответствующий ТУ 2416-00951501169-2005. Синтез МС проводили по методике, описанной в работе [6].

Анализ состава скипидара и продуктов ректификации проводили методом газовой хроматографии на приборе «Кристалл-Люкс 4000М» с пламенно-ионизационным детектором. Капиллярная колонка ZB-1 длиной 30 м и внутренним диаметром 0,25 мм; неподвижная фаза - ZB-1; толщина слоя фазы - 0,25 мкм; температура испарителя $-250^{\circ} \mathrm{C}$, детектора $-250^{\circ} \mathrm{C}$; программирование температуры колонки - от 50 (выдержка при начальной температуре - 5 мин) до $240{ }^{\circ} \mathrm{C}$, нагрев со скоростью $4{ }^{\circ} \mathrm{C} /$ мин; газ-носитель азот, расход газа - 2,0 мл/мин; расход водорода - 60 мл/мин; расход воздуха - 470 мл/мин. Объем вводимой пробы - 2 мкл. Идентификацию компонентов проводили по временам удерживания индивидуальных чистых веществ. Количественный расчет проводили методом нормализации.

Ректификацию проводили:

1. На лабораторной установке ректификации из стекла. Установка включает в себя колбонагреватель с регулятором напряжения, трехгорлую колбу (куб объемом 400 мл), колонку диаметром 20 мм и высотой 300 мм, заполненную пружинками из нержавеющей стали размером $2 \times 3$ мм, обратный холодильник, устройство деления отбора дистиллята и флегмы, прямой холодильник и приемную колбу.

2. На пилотной установке объемом 16 л периодического действия, изготовленной из стали Х18Н9Т. Диаметр колонны - 30 мм, высота насадочной части - 1200 мм, общая высота колонны - 1500 мм.

Необходимый вакуум создавали при помощи вакуумной станции Vacuum pumping unit PC 3003 Vario фирмы Vacuum brand GMBH.

\section{Обсуждение результатов}

В связи с поставленной целью необходимо было, в первую очередь, подобрать условия ректификации, в которых произойдет максимальное отделение терпинеолов, составляющих основу МС, от других компонентов. В таблице 1 (столбец 4) представлены данные о химическом составе МС-сырца. Видно, что в его состав входят $\alpha$-пинен, $\beta$-пинен, камфен и некоторые другие углеводороды, присутствующие в исходном скипидаре (табл. 1, столбец 3), в то же время в отличие от состава скипидара в МС-сырце появились продукты изомеризации пиненов, такие как терпинолен, дипентен, а также продукты гидратации - терпеновые спирты.

В условиях ректификации следует отогнать фракцию терпинеолов от исходного $\alpha$-пинена и терпеновых углеводородов (ТУВ). Учитывая известные литературные данные по температурам кипения компонентов МС-сырца и ректификации соснового масла-сырца $[2,4]$, подбирали условия для отделения самой низкокипящей в данном случае «пиненовой фракции», основу которой составляет $\alpha$-пинен, средней «фракции ТУВ», содержащей терпинолен, дипентен, $\Delta^{3}$-карен и некоторые другие ТУВ, и основной «спиртовой» фракции. Варьирование остаточного давления от 20 до 60 мбар при ректификации показало, что оптимальными условиями для разделения фракций являются интервалы температур, соответственно для пиненовой, ТУВ и спиртовой фракций: 1) 69-71 $\pm 0,5^{\circ} / 50 \pm 1$ мбар; 2) 71-98 $\pm 0,5^{\circ} / 50 \pm 1$ мбар; 3) 81-102 $\pm 0, \% 5^{\circ} / 20 \pm 1$ мбар.

При меньшем давлении для первой и второй фракций происходит плохое разделение компонентов фракций, а при более высоком давлении - «осмоление» органических жидкостей. Более низкое значение остаточного давления при выделении спиртовой фракции по сравнению с первой и второй фракцией связано с тем, что при нагревании МС-сырца до более высоких температур при большем остаточном давлении происходит заметное изменение цвета МС. Это наглядно иллюстрируют данные таблицы 2 об изменении цветности спиртовой фракции по Хазену [7] в зависимости от условий выделения спиртовой фракции: при увеличении остаточного давления от $20 \pm 1$ мбар до $40 \pm 1$ мбар, затем $60 \pm 1$ мбар в зависимости от флегмового числа 
показатель изменяется в интервале, соответственно, 5,7-15,2; 6,4-19,1; 25,6-36,2. В связи с этим после отделения фракции ТУВ необходимо немного охладить жидкость в кубе, а затем уменьшить остаточное давление.

В серии из десяти партий ректификации МС-сырца состав спиртовой фракции изменялся незначительно. Это следует из данных таблицы 1 (столбец 6), что свидетельствует о хорошей сходимости результатов. Условия ректификации были воспроизведены на пилотной установке с большими объемами МСсырца. Состав фракций при этом практически не отличался от такового при ректификации на лабораторной установке. Результаты определения цветности по Хазену для МС, полученного на пилотной установке, немного отличаются от таковых для лабораторной стеклянной установки, особенно при небольшом разре-

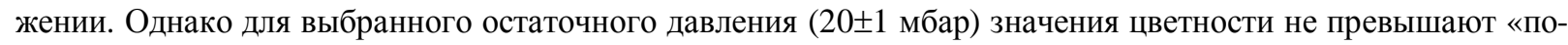
рогового» значения для соснового масла (табл. 3).

Для выделенных после ректификации фракций масла были определены важные технические характеристики, представленные в таблице 4 , которые будут основой для разработки нормативных документов на продукты.

Следует отметить, что лабораторная технология ректификации МС-сырца для получения слабоокрашенного МС является фрагментом разработки технологии получения в едином технологическом потоке продуктов переработки скипидара: соснового масла, терпингидрата, парфюмерного терпинеола и др. [4]. В связи с этим важно, что пиненовая фракция после ректификации будет возвращена на стадию гидратации $\alpha$-пинена $[4,6]$, а фракция ТУВ представляет собой самостоятельный коммерческий продукт, используемый как органический растворитель.

Таблица 1. Данные хроматографического анализа состава органических смесей

\begin{tabular}{|c|c|c|c|c|c|}
\hline \multirow[b]{2}{*}{ Компонент } & \multicolumn{5}{|c|}{ Состав образца, \% } \\
\hline & скипидар & МС-сырец & $\begin{array}{c}\text { пиненовая } \\
\text { фракция }\end{array}$ & фракция ТУВ & $\begin{array}{c}\text { спиртовая } \\
\text { фракция }\end{array}$ \\
\hline Трициклен & 0,30 & 0,25 & $0,58-0,65$ & - & - \\
\hline$\alpha$-Пинен & 90,70 & 37,90 & $85,52-93,25$ & $5,60-6,20$ & - \\
\hline Камфен & 2,40 & 0,70 & $5,82-6,47$ & $1,50-1,70$ & - \\
\hline$\beta$-Пинен & 2,30 & 0,04 & $0,028-0,32$ & $0,06-0,07$ & - \\
\hline Мирцен & 0,35 & 0,35 & $0,23-0,27$ & $1,60-1,62$ & - \\
\hline$\Delta^{3}$-Карен & 2,50 & 4,06 & $1,16-1,18$ & $22,05-23,55$ & - \\
\hline$\alpha$-Терпинен & 0,06 & 0,50 & $0,05-0,06$ & $3,00-3,20$ & - \\
\hline$n$-цимол & 0,04 & 0,13 & $0,02-0,03$ & $1,00-1,12$ & $0,05-0,01$ \\
\hline 1,8-Цинеол & 0,06 & 1,23 & - & $6,77-7,35$ & - \\
\hline Дипентен & 0,30 & 4,00 & $0,30-0,32$ & $25,30-26,95$ & $0,40-0,42$ \\
\hline$\gamma$-Терпинен & - & 0,30 & - & $2,33-2,50$ & - \\
\hline Терпинолен & - & 6,60 & - & $22,55-23,40$ & $0,75-0,80$ \\
\hline Фенхол & - & 0,71 & - & $0,20-0,22$ & $2,10-2,25$ \\
\hline Терпинен-1-ол & - & 1,42 & - & - & $5,10-5,65$ \\
\hline Цис- $\beta$-терпинеол & - & 1,44 & - & - & $4,20-4,65$ \\
\hline Изоборнеол & - & 0,18 & - & - & $0,60-0,64$ \\
\hline Борнеол & - & 0,89 & - & - & $3,18-3,45$ \\
\hline Терпинен-4-ол & - & - & - & - & $1,82-2,00$ \\
\hline$\alpha$-Терпинеол & - & 28,2 & - & - & $62,15-62,55$ \\
\hline$\gamma$-Терпинеол & - & 4,50 & - & - & $10,05-10,15$ \\
\hline
\end{tabular}

Таблица 2. Данные о цветности по шкале Хазена для фракций терпинеолов при ректификации на лабораторной установке

\begin{tabular}{c|c|c|c|c}
\hline $\begin{array}{c}\text { № } \\
\text { опыта }\end{array}$ & $\begin{array}{c}\text { Остаточное давление, } \\
\text { мбар }\end{array}$ & $\begin{array}{c}\text { Температура отбора } \\
\text { фракции, }{ }^{\circ} \mathrm{C}\end{array}$ & $\begin{array}{c}\text { Флегмовое число } \\
\text { Хазена, мг Рt/л }\end{array}$ \\
\hline 1 & 20 & $82-103$ & 5 & 5,7 \\
2 & 20 & $82-103$ & 2 & 9,4 \\
3 & 20 & $82-103$ & 0 & 15,2 \\
4 & 40 & $102-119$ & 5 & 6,4 \\
5 & 40 & $102-119$ & 2 & 10,8 \\
6 & 40 & $102-119$ & 0 & 25,1 \\
7 & 60 & $115-132$ & 5 & 30,5 \\
8 & 60 & $115-132$ & 2 & 36,2 \\
\hline
\end{tabular}


Таблица 3. Данные о цветности по шкале Хазена для фракций терпинеолов при ректификации на пилотной установке

\begin{tabular}{c|c|c|c|c}
\hline № опыта & $\begin{array}{c}\text { Остаточное давление, } \\
\text { мбар }\end{array}$ & $\begin{array}{c}\text { Температура отбора } \\
\text { фракции, }{ }^{\circ} \mathrm{C}\end{array}$ & $\begin{array}{c}\text { Цветность по шкале } \\
\text { Хазена, мг Рt/л }\end{array}$ \\
\hline 1 & 20 & $80-101$ & 5 & 11,2 \\
2 & 20 & $80-101$ & 2 & 15,3 \\
3 & 20 & $80-101$ & 0 & 23,2 \\
4 & 40 & $101-117$ & 5 & 10,8 \\
5 & 40 & $101-117$ & 2 & 24,8 \\
6 & 40 & $101-117$ & 0 & 14,3 \\
7 & 60 & $114-131$ & 10 & 26,1 \\
8 & 60 & $114-131$ & 5 & 30,3 \\
9 & 60 & $114-131$ & 2 & 36,7 \\
\hline
\end{tabular}

Таблица 4. Характеристики фракций ректификации соснового масла-сырца

\begin{tabular}{c|l|c|c|c|c}
\hline № & \multicolumn{1}{|c|}{ Наименование показателей } & $\begin{array}{c}\text { Пиненовая } \\
\text { фракция }\end{array}$ & ТУВ & $\begin{array}{c}\text { Спиртовая } \\
\text { фракция }\end{array}$ & $\begin{array}{c}\text { Нормативный доку- } \\
\text { мент }\end{array}$ \\
\hline 1 & Плотность при $20^{\circ} \mathrm{C}$, г $/ \mathrm{cm}^{3}$ & 0,860 & 0,841 & 0,930 & ГОСТ 18995.1-72 \\
2 & Кислотное число, мг КОН на 1 г продукта & 0,01 & 0,01 & - & ГОСТ 17823.1-72 \\
3 & Показатель преломления при $20^{\circ} \mathrm{C}$ & 1,4650 & 1,4820 & 1,4815 & ГОСТ 18995.2-2-73 \\
4 & Цветность по Хазену & - & - & 15 & ASTM D 5386 \\
\hline
\end{tabular}

\section{Bbыводы}

1. Разработана лабораторная методика получения слабоокрашенного соснового масла с цветностью по шкале Хазена не более 30.

2. Показано, что лабораторная методика воспроизводится на пилотной установке периодического действия.

\section{Список литературы}

1. Breitmaier E. Terpenes. Flavors, Fragrances, Pharmaca, Pheromones. Wiley-VCH Verlag GmbH, 2006. 223 p.

2. Гордон Л.В., Скворцов С.О., Лисов В.И. Технология и оборудование лесохимических производств. М., 1988. $356 \mathrm{c}$.

3. Новый справочник химика и технолога. Сырье и продукты промышленности органических и неорганических веществ. СПб., 2002. С. 1144.

4. Радбиль А.Б., Ильичев И.С., Шалашова А.А., Семенычева Л.Л. Глубокая переработка жидкофазных отходов лесной промышленности для создания новых материалов // Все материалы. Энциклопедический справочник. 2013. Вып. 11. С. 49-55.

5. Радбиль А.Б., Семенычева Л.Л., Ильичев И.С., Шалашова А.А., Маврина Е.А. Оптимизация процесса кислотно-каталитической гидратации скипидара // Вестник ННГУ им. Н.И. Лобачевского. 2014. №2(1). С. 87-90.

6. Радбиль А.Б., Долинский Т.И., Ильичев И.С., Шалашова А.А., Маврина Е.А., Семенычева Л.Л. Разработка лабораторной технологии кислотно-каталитической гидратации сульфатного скипидара в присутствии ортофосфорной кислоты для получения соснового масла // Вестник ННГУ им. Н.И. Лобачевского. 2014. №4. C. 130-134.

7. ГОСТ 29131-91 Продукты жидкие химические. Метод измерения цвета в единицах Хазена (платинокобальтовая шкала). М., 2004.

Поступило в редакциюю 22 октября 2014 г.

После переработки 24 марта 2015 2. 
Dolinsky T.I. ${ }^{1}$, Ilichev I.S. ${ }^{1}$, Novoselov A.S. ${ }^{2}$, Mavrina E.A. ${ }^{2}$, Shalashova A.A. ${ }^{2}$, Semenycheva L.L. ${ }^{2} *$ CONDITIONS DEVELOPMENT OF LOW COLORED PINE OIL PRODUCTION

${ }^{I}$ Trade House «Orgkhim», JSC (Private), pr. Gagarina, 29d, Nizhny Novgorod, 603950 (Russia)

${ }^{2}$ Nizhny Novgorod State University, pr. Gagarina, 23, Nizhny Novgorod, 603950 (Russia), e-mail: llsem@yandex.ru

The article presents data on the conditions of obtaining light-colored pine oil pine oil raw with color less than 30 Hazen scale. As the object of studies have used sulphate turpentine Ust-Ilim LPK corresponding TU 2416-009-51501169-2005. Synthesis of MS performed by a known procedure, quantitative analysis of the products of turpentine and distillation was carried out by gas chromatography instrument "Kristall 4000M Lux" with a flame ionization detector. Selection conditions rectification of crude tall oil was carried out using a laboratory setup of the glass and batch pilot plant. The composition of the fractions with virtually no different in the distillation in a laboratory and pilot plant. Data rectification reproduced well in a series of experiments. Terpineol is the latest perfume distillation fraction, previous fractions have an independent value. Lab Technology MC distillation of crude to produce light-colored fragment $\mathrm{MC}$ is developing technology for production in a single process stream processing products turpentine: pine oil, terpine, perfumery terpineol and others.

Keywords: terpene, hydrocarbons, sulfate turpentin, pine oil, perfumery terpineol, rectification, fraction.

\section{References}

1. Breitmaier E. Terpenes. Flavors, Fragrances, Pharmaca, Pheromones. Wiley-VCH Verlag GmbH, 2006, 223 p.

2. Gordon L.V., Skvorcov S.O., Lisov V.I. Tekhnologiia i oborudovanie lesokhimicheskikh proizvodstv. [Technology and equipment wood chemical industry]. Moscow. 1988, 356 p. (in Russ.).

3. Novyj spravochnik himika i tehnologa. Syr'e i produkty promyshlennosti organicheskih i neorganicheskih veshhestv. [The new directory Chemist and technologist. Raw materials and products of industrial organic and inorganic substances]. Saint Petersburg, 2002, p. 1144. (in Russ.).

4. Radbil' A.B., Il'ichev I.S., Shalashova A.A., Semenycheva L.L. Vse materialy. Jenciklopedicheskij spravochnik, 2013, no. 11, pp. 49-55. (in Russ.).

5. Radbil' A.B., Semenycheva L.L., Il'ichev I.S., Shalashova A.A., Mavrina E.A. Vestnik NNGU im. N.I. Lobachevskogo, 2014, no. 2(1), pp. 87-90. (in Russ.).

6. Radbil' A.B., Dolinskij T.I., Il'ichev I.S., Shalashova A.A., Mavrina E.A., Semenycheva L.L. Vestnik NNGU im. N.I. Lobachevskogo, 2014, no. 4, pp. 130-134. (in Russ.).

7. GOST 29131-91 Produkty zhidkie himicheskie. Metod izmerenija cveta v edinicah Hazena (platino-kobal'tovaja shkala). [State Standard 29131-91 liquid chemical products. The method of measuring color in Hazen units (platinum-cobalt scale)]. Moscow, 2004. (in Russ.).

Received 22 October 2014

Revised March 24, 2015

\footnotetext{
* Corresponding author.
} 
